
as follows:

The three species and their forms discussed in this paper may be listed

\author{
GLUPHISIA Bdv. \\ lintneri Grt. \\ o form pretians Franc. \\ avimacula Hudson \\ q form slossoniae Pack. \\ severa (o form) Hy. Edw. \\ normal form normalis Dyar \\ form danbyi Neum.
}

\title{
FREDERICK WALLACE EDWARDS
}

Just before the annual meetings of the entomological societies in December, 1940, the first news of the death of Fred W. Edwards reached America. It seemed to me, at Philadelphia, that no single subject was discussed so much and with so many expressions of real sorrow and regret, as was this sad occurrence. The brief published accounts are incorrect in certain important details, and a short notice of his life and activities is herewith provided.

The advices that have come to hand indicate that Edwards passed away from a chronic illness on November 15, 1940, presumably at his home in Letchworth, Herts, England. Frederick Wallace Edwards was born at Old Fletton, Huntingtonshire, a suburb of Peterborough, Northamptonshire, on November 28, 1888. He was the son of Cephas Luther and Automella (Sargent) Edwards, on the father's side his ancestors having been of Welsh extraction, on his mother's of Huguenot. He attended Secondary School at Cambridge, 1901-1906, and Christ College, Cambridge University, 1906-1909, with an extra year of Agriculture in 1910. Still later, Cambridge University awarded him the degree of Doctor of Science. He passed the civil service examination for Second Class Assistant in Zoology at the British Museum (Natural History), joining the staff on November 24, 1910. During the thirty years of service he was advanced regularly until, at the time of his death, he was one of the Keepers of the Museum, in charge of the Diptera and some related fields.

On September 21, 1911, Edwards married Florence Mary Williams, of Shelford, Cambridge, at Shelford. The widow, with three daughters,-Joan (born 1915), Hazel (1921), and Iris (1924)-survive, During his life Edwards made several trips to continental Europe, either for the purpose of collecting or of studying type materials. In 1913 he visited Switzerland; at Easter 1923, Paris, examining the extant types of Meigen and Macquart; in July 1923, six weeks in Scandinavia, collecting and studying the types of Zetterstedt, Fabricius, Fallen, and Staeger; in 1924, Holland, examining the types of van der Wulp and de Meijere. In 1925 he took an extended collecting trip, with Barnes, in Switzerland, the Black Forest, and the Tyrol, attending the Entomological Congress at Zurich, and studying the Winnertz types at Bonn. In 1926, he took his first trip abroad, sailing on September 23 from Tilbury for Buenos Aires, where he and Mrs. Edwards arrived on October 16, being met at the dock by Raymond and Elnora Shannon. The party left three days later for southern Patagonia, leaving southern Chile on the return trip on December 25. The results of the Edwards-Shannon expedition to Patagonia and South Chile have been published in a series of volumes and parts that has revolutionized our knowledge of the Diptera of the region (British Museum, 1929-date).

At Easter, 1928, the Edwards spent three weeks in Corsica; in July he made his only visit to the United States and Canada while a delegate to the Fourth International Entomological Congress at Ithaca, New York. At this time, the 
Edwards spent five days with me at Amherst, August 7-11. At the conclusion of the Congress they visited Dyar in Washington, sailing for home at the end of August. In 1929, trips were made to the English Lake District (Windermere) and to Killarney, Ireland; in 1931, to Rannoch, Scotland; in 1932, again to Scotland and to the Entomological Congress at Paris; in 1933, to Germany and Latvia, visiting Lackschewitz in August; in 1934, to Scotland and to Pembrokeshire in south Wales. In 1934-1935, Edwards took his third and last trip abroad, this time as joint leader of the British Museum Ruwenzori Expedition to the high mountains of tropical Africa, the scientific results of which are now being published by the authorities of the British Museum. Later in 1935, he made a trip to Spain, while attending the Sixth International Entomological Congress, with brief opportunities for collecting in the Pyrenees.

In later years, more and more of his summer vacations were spent with his wife and daughters in various parts of Britain.

As early as February, 1939, there began the series of fears and worries that reached a culmination in the outbreak of the actual hostilities of the present war. My last letter from him, dated September 22, 1940, gave a slight hint of his condition, when he indicated that he had been to the doctor for indigestion but that he did not believe anything very serious was wrong. Thus ended a series of letters dating from the earliest days at the Museum in 1911.

It is impossible to state at this time how many papers Edwards has published, or how many new species he has described. In December, 1931, he gave an estimate of possibly 175 papers, and it seems certain that his total will far exceed 200, all of the very highest calibre. Edwards had a most remarkable eye for detailed and important characters in insects. A seemingly casual glance appeared sufficient to impress on his mind all the essential characters of a given species. While visiting me at Amherst in 1928, I had ample opportunity to watch his methods. During the few days he was here, he examined hundreds of cases of specimens, carefully scrutinizing the contents of each and jotting down an occasional note. The result was an almost incredible knowledge of the contents, sufficient to provide hours of discussion on a given species or group of forms. If there is anything like a "photographic eye" then certainly Edwards possessed such to a marvellous degree.

Fred Edwards has passed on, but the work that he has accomplished and his influence on a host of fellow workers in the Diptera will remain indefinitely. His world-wide grasp of many of the most difficult families in the Nematocera,the Tipulidae, Culicidae, Chironomidae, Cecidomyiidae, Mycetophilidae, Blepharoceridae, and others-has assured him of a high ranking in the brilliant group of Dipterologists who have passed on, including among others of somewhat comparable attainments, Meigen, Wiedemann, Zetterstedt, Macquart, Loew, Osten-Sacken, Schiner, Skuse, Verrall, Kertész, Bezzi, Williston, Aldrich, and Lackschewitz. One cannot but wonder when the World will see another of the brilliant attainments of Fred Edwards.

$$
\text { C. P. Alexander, }
$$
Amherst, Mass. 